\title{
Research progress on combat trauma treatment in cold regions
}

Hui-Shan Wang ${ }^{*}$ and Jin-Song Han

\begin{abstract}
Cold regions are a special combat environment in which low temperatures have a great impact on human metabolism and other vital functions, including the nervous, motion, cardiovascular, circulatory, respiratory, and urinary systems; consequently, low temperatures often aggravate existing trauma, leading to high mortality rates if rapid and appropriate treatment is not provided. Hypothermia is an independent risk factor of fatality following combat trauma; therefore, proactive preventative measures are needed to reduce the rate of mortality. After summarizing the basic research on battlefield environments and progress in the prevention and treatment of trauma, this article concludes that current treatment and prevention measures for combat trauma in cold regions are inadequate. Future molecular biology studies are needed to elucidate the mechanisms and relevant cell factors underlying bodily injury caused by cold environment, a research goal will also allow further exploration of corresponding treatments.
\end{abstract}

Keywords: Military medicine, Wounds and injuries, Cold climate, Body temperature

Atypical battlefield environments often differ from more common environments in combat trauma pattern, injury type, and the applied principles of treatment. Cold regions are a distinct type of battlefield environment that feature lengthy periods of extreme temperature differences, harsh conditions, multiple disease factors, various injury types, and a wide distribution of frozen soil, snow, ice, and complex terrain. The high impact of environmental factors (e.g., low temperature) often aggravates the original wound and may result in a higher mortality rate if suitable treatment is not rapidly applied. Furthermore, victim evacuation is often difficult, thereby significantly increasing both combat and non-combat casualties. In the Korean War, low temperature-induced non-combat attrition accounted for $20 \%$ of the total casualties in the People's Volunteer Army. Therefore, combat trauma treatment in cold regions is a key issue for military medicine research in the People's Liberation Army (PLA). Here, we reviewed the worldwide research progress of combat trauma treatment in cold regions.

\footnotetext{
* Correspondence: huishanwang@hotmail.com

Department of Cardiovascular Surgery, General Hospital of Shenyang Military Command, Shenyang 110016, China
}

\section{() BioMed Central}

\section{Basic research on the influence of cold environments on the body}

The most common source of temperature loss in trauma patients includes: exposure (environmental, as well as cavitary), the administration of i.v. fluids, and anesthesia which results in the loss of shivering mechanisms and decreases blood pressure [1]. The normal range in human body temperature is generally considered to be between $36.4-37.3^{\circ} \mathrm{C}$, and non-traumatic hypothermia is defined at a core body temperature between $32-35^{\circ} \mathrm{C}$. If injuries are involved, hypothermia is defined by a core body temperature below $35^{\circ} \mathrm{C}$. Mestre-Alfaro et al. [2] proposed that the human body is less adaptive to extreme cold than to high temperatures; low temperatures can cause frostbite, severely damage the cardiovascular, respiratory, urinary, immune and motor systems, and may even be life-threatening.

\section{The influence of a cold environment on the central nervous system}

A short stimulation of sympathetic nerves by a cold environment can enhance nerve tension and metabolic activity. With prolonged cold exposure, human motor and sensory neurons are also functionally suppressed, which leads to numbness and irreversible damages [3]. Kühlein 
et al. [4] experimentally demonstrated that cold injury can slow cranial nerve transduction and may indirectly intensify cold injury via oxidative damage, inducing brain edema, secondary brain injury, and apoptosis. Every $1^{\circ} \mathrm{C}$ reduction in body temperature corresponds to a decrease in cerebral blood flow by $6 \%-7 \%$, which can endanger the lives of patients sustaining traumatic brain injury.

\section{The influence of cold environment on the motor system}

Blondin and colleagues [5]. revealed that cold exposure can boost aerobic oxidation and energy metabolism in skeletal muscle, resulting in elevated heat generation to sustain body temperature. In addition, exposure to cold may cause dysfunction in the peripheral nervous system and correspondingly impair skin sensation, diminish muscle coordination, and decrease joint flexibility. Together, these impairments can result in torn muscles and tendons.

\section{The influence of cold environment on the cardiovascular system}

The early effects of hypothermia on the cardiovascular system include augmented heart rate, output, and mean arterial pressure. However, with continuing decrease in body temperature, other symptoms begin to emerge such as slowed heart rate, weak myocardial contractility, reduced output, and low blood pressure [6]. When body temperature drops below $33^{\circ} \mathrm{C}$, coronary blood flow begins to diminish, resulting in myocardial anoxia. Atrial fibrillation arises when body temperature falls below $30^{\circ} \mathrm{C}$, and ventricular fibrillation occurs when body temperature falls below $25^{\circ} \mathrm{C}$; cardiac arrest develops when body temperature falls below $24^{\circ} \mathrm{C}$. Hypothermia can also markedly increase rate of apoptosis in cardiomyocytes [7].

\section{The influence of cold environment on the circulatory system}

Sillesen et al. [8] revealed that injury-induced blood loss activates the coagulation system, thereby promoting the generation of blood clots to inhibit additional bleeding. Cold exposure can affect the coagulation cascade which ultimately damages platelet function. When body temperature declines to $32.8^{\circ} \mathrm{C}$, the activity of coagulation factor IV can be reduced by up to $33 \%$. Local tissue freezing significantly increases red blood cell numbers, hemoglobin, and capillary resistance, and then decreases the deformability of red blood cells, promotes leukocyte adhesion/activation, increases blood viscosity, and ultimately promotes the formation of thrombus. These changes can cause a vicious cycle leading to disturbances in the microcirculation of frostbite-affected tissue and eventually causing damage to the body [9]. Heart rate, respiratory rate, and blood pressure rise between normal and $32.2^{\circ} \mathrm{C}$, but decrease under the $32.2^{\circ} \mathrm{C}$; below $27.8^{\circ} \mathrm{C}$ the heart's rhythm becomes dangerously disordered.

\section{The influence of cold environment on the respiratory system}

The effects of cold exposure on the respiratory system include decreased respiratory cilia movement and increased respiratory secretions and viscosity [10]. Pulmonary edema may emerge if body temperature drops below $25^{\circ} \mathrm{C}$. Respiratory reflex stimulation typically accelerates during the early phase of hypothermia, which is followed by reduced respiration rate and tidal volume. Severe conditions can inhibit the medullary respiratory center and weaken tracheal and bronchial cilia movement, thereby causing injury to the airways.

\section{The influence of cold environment on the urinary system}

The early phase of hypothermia has a diuretic effect, which may be associated with peripheral vasoconstriction, inhibited antidiuretic hormone, and elevated central blood volume. However, if body temperature continues to drop below $32.2^{\circ} \mathrm{C}$, both renal blood flow and glomerular filtration rate decrease, which, if severe, may cause acute renal failure [11].

\section{The influence of cold environment on metabolism}

Low temperature could double the metabolic rate, which depletes energy reserves. If body temperature drops further, muscle tremors may occur. Muscle tremors boost the metabolic rate by 6 -fold compared to the resting state; thus, energy exhaustion is more pronounced. A further decrease in body temperature results in decreased blood flow, disrupting electrolyte and acid-base balances eventually causing hypoxic liver injury.

\section{Current research status of the impact of cold environment on combat trauma treatment}

In the pre-hospital environment, victims suffering from hypothermia in addition to moderate or severe brain injury caused by local, blunt trauma may show a 3-fold increase in mortality rate, and death may occur shortly after their arrival at the hospital. An examination of the Pennsylvania Interstate pre-hospital trauma database also revealed that injured patients aged 16 years or older displayed a similar rate of mortality if hypothermia developed. A retrospective analysis on 12-year burn patient data in New York showed that hypothermia is common among extensive burn patients, who also have a high mortality rate [12]. 


\section{Hypothermia is an independent risk factor for combat trauma-related death}

It has been proposed that hypothermia is an independent physiological predictor of pre-hospital death rates $[13,14]$. Arthurs et al. analyzed data from 2,848 patients who had been treated in a hospital for combat trauma, a sample in which $18 \%$ of the patients were hypothermic, and concluded that hypothermia was significantly correlated with the Glasgow Coma Scale (GCS), tachycardia, hypotension, lower hematocrit, and acidosis. If a victim is exposed in a cold environment, he or she may violently shiver and sustain a rapid dissipation of body heat via conduction, convection, and radiation; as a consequence, the ability to regulate core body temperature is lost. If body temperature drops below $32^{\circ} \mathrm{C}$, mortality rate can reach $21 \%$; furthermore, the same low body temperature along with bleeding caused by combat injury may result in a $100 \%$ death rate. Deaths caused by hypothermia are also associated with bleeding. Duan and colleagues. [15] argued that acute traumatic coagulopathy (ATC) is commonly seen among patients with severe injury and leads to uncontrolled bleeding diathesis, which is an important contributor to trauma death.

\section{Controversies}

There are still a few scholars who oppose the designation of hypothermia as an independent risk factor for trauma death, arguing that hypothermic patients are often accompanied by more severe diseases. Lapostolle $\mathrm{F}$ et al. [16] believed that the key risk factor for the onset of hypothermia were the severity of injury, but other factors such as environmental conditions and the emergency medical services provided were also significant. Changes in practice could help reduce the impact of factors such as infusion fluid temperature and mobile unit temperature. Nevertheless, this opinion has been challenged. Bukur et al. [17] first classified injured patients according to severity, further divided each injury level into sub-groups of different body temperatures, and assessed their diseases. The authors found that the rate of mortality was significantly different between the hypothermic and non-hypothermic groups, indirectly arguing against the theory that disease severity, but not hypothermia, leads to a high mortality rate.

\section{The prevention of hypothermia in cold environments}

Studies have revealed that in the early stages of combat trauma treatment, measures that effectively restore body temperature are imperative as they are conducive to improving the prognosis of combat trauma [18]. After the Korean War, the Afghanistan war represents another large-scale armed conflict in a cold region. A study was aimed to explore the extent of cold weather injuries in the military population [19]. 18,214 patients were involved in the study. 19 cases were identified cold-weather injury in the Afghanistan Conflict. Two cases of frostbite were identified with only 1 likely requiring surgical intervention. No cases occured in cold-weather injury in Iraq. The 19 cold-weather injuries were decreased greatly compared with the number of cold-weather injuries in the Korean War which is reported up to 6300 cases. This suggested that cold-weather injuries colud be prevented by the shorter and weather-dependent engagements, education about cold-weather, and improved equipment of the soliders.

\section{Common rewarming methods}

A simple method to address the damaging effects of cold temperature is to employ passive rewarming strategies. For example, patients should be rapidly evacuated from the cold environment, re-warmed using an insulation blanket, and covered with a woolen blanket in the ambulance rather than being exposed to the air and losing body heat during examination of the injury. This is important because once hypothermia occurs, there is no easy way to recover body temperature. The above method is only applicable for moderate hypothermia and is ineffective for patients whose thermoregulatory mechanisms are impaired. Currently, Hypothermia Prevention Management Kits are used by the United States Army to keep patients warm during their transfer [20]. More invasive re-warming methods require special devices and training; thus, they are unsuitable for temperature restoration in pre-hospital environments. The typical methods of such rewarming techniques include body core rewarming and body peripheral rewarming, where the former outperforms the latter. In addition, rewarming devices can also be used for airway warming, transfusion warming, or as a cover for surface rewarming. These devices may also be installed on an emergency or evacuation platform for mandatory ventilation rewarming. Another effective method of temperature maintenance is to place an insulated heating package on the patient's head, back, or armpit.

Under simulated battlefield conditions, the aforementioned methods reliably prevent hypothermia in animal models. Based on the Joint Theater Trauma System Clinical Practice Guideline (CPG), a study was designed to evaluate the effectiveness of CPG in treatment in the prevention of hypothermia-trauma complications. The results of this study revealed that the application of CPG can decrease the occurrence of hypothermia, where a woolen blanket is most frequently used during evacuation. Allen et al. [20] tested three active hypothermia prevention products, including the Hypothermia Prevention Management Kit (HPMK), Ready-Heat, and Bair Hugger, as well as five passive products (woolen blanket, 
space blanket, Blizzard blanket, human remains pouch, and Hot Pocket) [21]. Their results showed that the active products led to better outcomes than the passive methods, with HPMK showing the best results by maintaining significantly higher temperatures for $120 \mathrm{~min}$. The study also showed that the active prevention devices did not reach $44^{\circ} \mathrm{C}$, a temperature which damages human tissue, after 6 hours use. The best-performing passive products were the Hot Pocket and Blizzard blanket, which were able to sustain high temperatures for $120 \mathrm{~min}$. Hence, all of the active devices and most of the passive tools were superior to a woolen blanket. Under conditions close to room temperature, the Hot Pocket, Blizzard blanket, and other active devices were as effective as HPMK. Of course, ensuring that there is insulation between the victim and the ground or the stretcher is a top priority because the body can lose heat through conduction. Attention should also be paid to keeping the head and feet warm, as these areas lose most of the body heat. Lastly, it is important to note that the venous infusion of fluid at room temperature may rapidly decrease body temperature; therefore, fluids need to be warmed to at least $37.8^{\circ} \mathrm{C}$, or for hypothermic patients, $40.0-42.2^{\circ} \mathrm{C}$.

\section{The treatment of hypothermia in cold environments}

\section{The application of blood products in the coagulation} disorders treatment

The currently acknowledged lethal triad is comprised of hypothermia, metabolic acidosis, and coagulopathy [22]. Hypothermia usually comes together with and may aggravate acidosis and coagulopathy, which again may be associated with high mortality [1], especially in cold regions. Any one of these factors may lead to death if not properly treated. Coagulopathy resulting from severe trauma complicates the control of bleeding and therefore increases the rate of mortality in combat-wounded victims. Hypothermia can lead to coagulation disorders, which increase the incidence of bleeding and "non-fatal triad" as is in the non-cold regions. Take an experimental study for example [23], 40 Sprague-Dawley rats were used to established a model for uncontrolled bleeding by being exposed to a femoral artery injury, and allocated to normal temperature group or hypothermia group. The hypothermic group was cooled to $30^{\circ} \mathrm{C}$ and then rewarmed after $90 \mathrm{~min}$. The volume of bleeding was recorded. There was no difference between groups during the initial bleeding. These rebleeding volumes accounted for about $41 \%$ of total blood volume in the hypothermic group, while the corresponding figure for the normothermic rebleeders was only $3 \%$ of blood volume $(P<0.001)$. This study demonstrated that the risk of rebleeding from a femoral injury is greater in the presence of hypothermia and suggests that factors other than temperature- induced coagulopathy also contributed to the increased hemorrhage.

Shock promotes the initiation of early coagulation pathways in which damaged tissues release thrombuslike substances and activate anticoagulation systems; coagulopathy is closely linked to subsequent treatments for acidosis, hypothermia, and hemodilution [24]. The prompt treatment of hypothermia is needed to correct the coagulopathy, thereby avoiding the occurrence of catastrophic and fatal disseminated intravascular coagulation (DIC). Methods to treat coagulopathy include infusion of recombinant activated factor VII (rFVIIa) or fresh whole blood. In addition, treatment with tranexamic acid (TXA) can decrease the mortality of patients who have been hospitalized for $>30 \mathrm{~d}$. Treatment of combat-wounded victims at the 31st Combat Support Hospital (31st CSH) in Baghdad between 2004-2005 revealed that there were some advantages to using fresh whole blood at $20-24^{\circ} \mathrm{C}$; military doctors proposed that whole blood should be used under extreme conditions with low temperatures. Farrugia et al. [25] propose that in large-volume hemorrhage, fresh whole blood in may be superior to whole blood that has been reconstituted from multiple individual components. Nevertheless, research conducted by the United States Army revealed that between March 2003 and July 2007, over 6,000 units of warm fresh whole blood were used for transfusion in field hospitals of Afghanistan and Iraq. By December 2008, 20 patients became infected with hepatitis because of whole blood transfusion [26]. As a consequence, the United States Army Medical Department issued an order that fresh whole blood can only be used if there is no other blood source.

\section{Controlled hypothermia}

Damage control resuscitation is a standard pre-hospital treatment method in field hospitals. With a basic strategy of low pressure, low capacity, delaying, and low temperature, this technique emphasizes the principles of field medicine: "forward-looking and strengthening, having advanced equipment, and focusing on emergency." In this way, medical staff can provide advanced trauma support for combat treatment. The invention and application of respiratory and circulatory support technologies developed by the United States Army during the Gulf War are the most prominent breakthrough in combat injury treatment. Such therapeutically low temperatures are different than those induced in cold environments, constituting an active method to achieve controlled low temperature; by adjusting fluid resuscitation to a lower than normal body temperature, this technique extends the ideal treatment window for hemorrhagic patients to receive life-saving hemostasis and resuscitation. 
Baron Dominique-Jean Larrey (1766-1842) was the first to propose hypothermia as a therapeutic method [27]. To test the feasibility of the cardiopulmonary bypass/extracorporeal membrane oxygenation (CPB/ECMO) system which was designed at the Cleveland Clinic Foundation's (CCF), a study was conducted by a porcine model mimics frontline combat wounds [28]. The animals were induced with lethal massive hemorrhage of the major blood vessels and underwent repair of the blood vessels under a state of deep hypothermic arrest by CCF. The animals survivedt and were monitored for neurological conditions, cognitive function, the damage of vital organs, and complications after 3 weeks. $83 \%$ of the test animals survived. and there was no significant difference in neurological impact, organ dysfunction, or complication occurrence between the treatment outcomes and the conventional equipment. Therefore, the CCF/CPB/ECMO system can be employed to facilitate the repair of lethal major vascular injuries through deep hypothermia, especially for those wounded under harsh conditions.

Furthermore, hypothermia therapy is also used for cerebral hypoperfusion after cardiopulmonary resuscitation in clinical practice. For instance, Pacini et al. [29] pointed out that antegrade selective cerebral perfusion (ASCP) with moderate hypothermia at $26^{\circ} \mathrm{C}$ provides good brain protection during aortic arch surgery. Moreover, during circulatory arrest, moderate hypothermia also offers good protection of visceral organs within the limited periods (<60 min) of visceral ischaemia, by the means of reducing the systemic inflammatory response and the reperfusion organ injury. It was also suggested that ASCP) and mild systemic hypothermic circulatory arrest can be safely applied to complex aortic arch surgery even in a subgroup of patients with up to 90 minutes of antegrade cerebral perfusion (ACP) [30]. Unilateral ACP might be advantageous than bilateral ACP in that it reduces the incidence of embolism arising from surgical manipulation on the arch vessels. Zierer et al. [31] believed that unilateral ACP in a pressure-controlled manner during mild systemic hypothermia is a safe protection strategy in elective aortic arch surgery.

Taken together, the current treatment and prevention measures for combat trauma in cold environments remain open for improvement. In the future, molecular techniques are needed to elucidate the mechanisms underlying body injury due to the cold environment, including the study of cell factors associated with cold trauma and the further exploration of relevant prevention methods.

\section{Abbreviations}

ACP: Antegrade cerebral perfusion; ASCP: Antegrade selective cerebral perfusion; ATC: Acute traumatic coagulopathy; CCF: Cleveland Clinic Foundation's; CPB/ECMO: Cardiopulmonary bypass/extracorporeal membrane oxygenation; CPG: Clinical practice guideline; CSH: Combat Support Hospital; DIC: Disseminated intravascular coagulation; GCS: Glasgow coma scale;
HPMK: Hypothermia prevention management kit; PLA: People's Liberation Army; rFVIla: Recombinant activated factor VII; TXA: Tranexamic acid.

\section{Competing interest}

The authors declare that they have no competing interests.

\section{Authors' contributions}

$\mathrm{H}-\mathrm{SW}$ and J-SH, contributed equally to this work. Both authors read and approved the final manuscript.

Received: 17 April 2014 Accepted: 17 April 2014

Published: 1 May 2014

\section{References}

1. Søreide $\mathrm{K}$ : Clinical and translational aspects of hypothermia in major trauma patients: from pathophysiology to prevention, prognosis and potential preservation. Injury 2014, 45:647-654.

2. Mestre-Alfaro A, Ferrer MD, Banquells M, Riera J, Drobnic F, Sureda A, Tur JA, Pons A: Body temperature modulates the antioxidant and acute immune responses to exercise. Free Radic Res 2012, 46:799-808.

3. Sabir H, Scull-Brown E, Liu X, Thoresen M: Immediate hypothermia is not neuroprotective after severe hypoxia-ischemia and is deleterious when delayed by 12 hours in neonatal rats. Stroke 2012, 43:3364-3370.

4. Kühlein HN, Tegeder I, Möser C, Lim HY, Häussler A, Spieth K, Jennes I, Marschalek R, Beckhaus T, Karas M, Fauth M, Ehnert C, Geisslinger G, Niederberger E: Nerve injury evoked loss of latexin expression in spinal cord neurons contributes to the development of neuropathic pain. PLoS One 2011, 6:e19270.

5. Blondin DP, Maneshi A, Imbeault MA, Haman F: Effects of the menstrual cycle on muscle recruitment and oxidative fuel selection during cold exposure. J Appl Physiol 2011, 111:1014-1020.

6. Perl T: Pathophysiology and epidemiology of accidental hypothermia. Biomed Tech 2012, 57:1035.

7. Diestel A, Drescher $\mathrm{C}$, Miera O, Berger F, Schmitt KR: Hypothermia protects $\mathrm{H} 9 \mathrm{c} 2$ cardiomyocytes from $\mathrm{H}_{2} \mathrm{O}_{2}$ induced apoptosis. Cryobiology 2011, 62:53-61.

8. Sillesen $M$, Rasmussen $L S$, Jin $G$, Jepsen $C H$, Imam A, Hwabejire JO, Halaweish I, DeMoya M, Velmahos G, Johansson PI, Alam HB: Assessment of coagulopathy, endothelial injury, and inflammation after traumatic brain injury and hemorrhage in a porcine model. $J$ Trauma Acute Care Surg 2014, 76:12-19. discussion 19-20.

9. Watanabe MA, Kucenas S, Bowman TA, Ruhlman M, Knuepfer MM: Angiotensin II and CRF receptors in the central nucleus of the amygdala mediate hemodynamic response variability to cocaine in conscious rats. Brain Res 2010, 1309:53-65.

10. Sundar IK, Yao H, Huang Y, Lyda E, Sime PJ, Sellix MT, Rahman I: Serotonin and corticosterone rhythms in mice exposed to cigarette smoke and in patients with COPD: implication for COPD-associated neuropathogenesis. PLoS One 2014, 9:e87999.

11. Kansagra A, Patel S, Wilcox SR: Prolonged hypothermia due to olanzapine in the setting of renal failure: a case report and review of the literature. Ther Adv Psychopharmacol 2013, 3:335-339.

12. Singer AJ, Taira BR, Thode HC Jr, McCormack JE, Shapiro M, Aydin A, Lee C: The association between hypothermia, prehospital cooling, and mortality in burn victims. Acad Emerg Med 2010, 17:456-459.

13. Shere-Wolfe RF1, Galvagno SM Jr, Grissom TE: Critical care considerations in the management of the trauma patient following initial resuscitation. Scand J Trauma Resusc Emerg Med 2012, 20:68.

14. Karlsen AM, Thomassen O, Vikenes BH, Brattebø G: Equipment to prevent, diagnose, and treat hypothermia: a survey of Norwegian pre-hospital services. Scand I Trauma Resusc Emerg Med 2013, 21:63.

15. Duan K, Yu W, Li N: The pathophysiology and management of acute traumatic coagulopathy. Clin Appl Thromb Hemost 2013, [Epub ahead of print].

16. Lapostolle F, Sebbah JL, Couvreur J, Koch FX, Savary D, Tazarourte K, Egman G, Mzabi L, Galinski M, Adnet F: Risk factors for onset of hypothermia in trauma victims: the Hypo Traum study. Crit Care 2012, 16:R142.

17. Bukur M, Kurtovic S, Berry C, Tanios M, Ley EJ, Salim A: Pre-hospital hypothermia is not associated with increased survival after traumatic brain injury. J Surg Res 2012, 175:24-29. 
18. Hildebrand F, Probst C, Frink M, Huber-Wagner S, Krettek C: Importance of hypothermia in multiple trauma patients. Unfallchirurg 2009, 112:959-964.

19. Hall A, Evans K, Pribyl S: Cold injury in the United States military population: current trends and comparison with past conflicts. I Surg Educ 2010, 67:61-65

20. Allen PB, Salyer SW, Dubick MA, Holcomb JB, Blackbourne LH: Preventing hypothermia: comparison of current devices used by the US army in an in vitro warmed fluid model. J Trauma 2010, 69:S154-S161.

21. Nesbitt M, Allen P, Beekley A, Butler F, Eastridge B, Blackbourne L: Current practice of thermoregulation during the transport of combat wounded. J Trauma 2010, 69:S162-S167.

22. Hanke AA, Rahe-Meyer N: Trauma-induced coagulopathy. Unfallchirurg 2014, 117:95-98.

23. Heinius $G$, Hahn RG, Sondén A: Hypothermia increases rebleeding during uncontrolled hemorrhage in the rat. Shock 2011, 36:60-66.

24. Bergeron JW: The crucifixion of Jesus: review of hypothesized mechanisms of death and implications of shock and trauma-induced coagulopathy. J Forensic Leg Med 2012, 19:113-116.

25. Farrugia A, Vamvakas E: Toward a patient-based paradigm for blood transfusion. J Blood Med 2014, 31:5-13.

26. Spinella PC: Warm fresh whole blood transfusion for severe hemorrhage: U.S. military and potential civilian applications. Crit Care Med 2008, 36:S340-S345.

27. Remba SJ, Varon J, Rivera A, Sternbach GL: Dominique-jean larrey: the effects of therapeutic hypothermia and the first ambulance. Resuscitation 2010, 81:268-271.

28. Casas F, Alam H, Reeves A, Chen Z, Smith WA: A portable cardiopulmonary bypass/extracorporeal membrane oxygenation system for the induction and reversal of profound hypothermia: feasibility study in a Swine model of lethal injuries. Artif Organs 2005, 29:557-563.

29. Pacini D, Pantaleo A, Di Marco L, Leone A, Barberio G, Murana G, Castrovinci S, Sottili S, Di Bartolomeo R: Visceral organ protection in aortic arch surgery: safety of moderate hypothermia. Eur J Cardiothorac Surg 2014 [Epub ahead of print].

30. Zierer A, El-Sayed Ahmad A, Papadopoulos N, Moritz A, Diegeler A, Urbanski PP: Selective antegrade cerebral perfusion and mild $\left(28^{\circ} \mathrm{C}-30^{\circ} \mathrm{C}\right)$ systemic hypothermic circulatory arrest for aortic arch replacement: results from 1002 patients. J Thorac Cardiovasc Surg 2012, 144:1042-1049.

31. Zierer A, Risteski P, E-Sayed Ahmad A, Moritz A, Diegeler A, Urbanski PP: The impact of unilateral versus bilateral antegrade cerebral perfusion on surgical outcomes after aortic arch replacement: a propensity-matched analysis. J Thorac Cardiovasc Surg 2014, 147:1212-1218.

doi:10.1186/2054-9369-1-8

Cite this article as: Wang and Han: Research progress on combat trauma treatment in cold regions. Military Medical Research 2014 1:8.

\section{Submit your next manuscript to BioMed Central and take full advantage of:}

- Convenient online submission

- Thorough peer review

- No space constraints or color figure charges

- Immediate publication on acceptance

- Inclusion in PubMed, CAS, Scopus and Google Scholar

- Research which is freely available for redistribution

Submit your manuscript at www.biomedcentral.com/submit
C Biomed Central 